\title{
Synthesis and Characterization of YAG Nanoparticles by Ultrasound-Assisted and Ultrasound-Microwave-Assisted Alkoxide Hydrolysis Precipitation Methods
}

\author{
Wei Si, ${ }^{1}$ Chao Ding, ${ }^{2}$ and Siqi Ding ${ }^{3}$ \\ ${ }^{1}$ School of Materials Science and Engineering, Dalian Jiaotong University, Dalian 116028, China \\ ${ }^{2}$ Dalian Environmental Monitoring Center, Dalian 116023, China \\ ${ }^{3}$ School of Civil Engineering, Dalian University of Technology, Dalian 116024, China \\ Correspondence should be addressed to Wei Si; siwei@djtu.edu.cn
}

Received 25 September 2014; Accepted 5 December 2014; Published 28 December 2014

Academic Editor: Claude Estournès

Copyright (C) 2014 Wei Si et al. This is an open access article distributed under the Creative Commons Attribution License, which permits unrestricted use, distribution, and reproduction in any medium, provided the original work is properly cited.

\begin{abstract}
Yttrium aluminum garnet (YAG, $\mathrm{Y}_{3} \mathrm{Al}_{5} \mathrm{O}_{12}$ ) nanoparticles were synthesized by ultrasound-assisted and ultrasound-microwaveassisted alkoxide hydrolysis precipitation methods. The effect of reaction parameters including $\mathrm{pH}$ value, ultrasonic radiation time, and calcination temperature on the composition of the products was investigated. The YAG nanoparticles and their precursor were characterized by X-ray powder diffraction (XRD), differential thermal analysis (DTA), Fourier-transform infrared spectroscopy (FT-IR), and high-resolution transmission electron microscopy (HRTEM). The results show that the single ultrasound-assisted method to synthesize YAG phase often contains intermediate phases of YAM $\left(\mathrm{Y}_{4} \mathrm{Al}_{2} \mathrm{O}_{9}\right)$ and YAP $\left(\mathrm{YAlO}_{3}\right)$; pure YAG phase can form only at special conditions and as single crystal. The pure phase YAG powders can be obtained at each experimental condition when using ultrasound-microwave-assisted synthesis and the grain is polycrystalline. This is due to the microwave radiation which promotes atomic diffusion and forms a lot of crystal nuclei of YAG in the precursor. The YAG nanoparticles with a grain size of $18 \mathrm{~nm}$ can be obtained at a calcination temperature of $900^{\circ} \mathrm{C}$ when using ultrasound-microwave-assisted method.
\end{abstract}

\section{Introduction}

Yttrium aluminum garnet ( $\mathrm{YAG}, \mathrm{Y}_{3} \mathrm{Al}_{5} \mathrm{O}_{12}$ ) is an important laser material with excellent chemical stability, thermal and good optical properties, and high temperature creep resistance. It has proved to be one of the most promising laser materials for many kinds of laser devices [1-3].

In order to achieve high density and highly transparent YAG ceramics, highly dispersed ultrafine YAG powder is necessary [4-6]. At present, several wet chemical synthesis methods have been developed and successfully used for low temperature production of pure phase YAG powders [7-9]. These methods include the coprecipitation [10,11], homogeneous precipitation [12], and sol-gel combustion [13, 14].

Among all of the used physicochemical techniques, sonochemical reactions, utilizing unique phenomena induced by ultrasonic cavitation, have shown to be very promising in the preparation of nanostructured materials [15-17]. The technique stemmed from acoustic cavitation. The formation, growth, and implosive collapse of bubbles in a liquid cause intense local heating $\left(5000^{\circ} \mathrm{C}\right)$ and pressure $(1800 \mathrm{~atm})$. Moreover, the ultrasound waves induce the formation of radicals which results in enhanced reaction rates at ambient temperatures. It has also been shown that much smaller nanoparticles and higher surface area can be achieved through intense conditions [18]. Furthermore, the use of microwave irradiation for the preparation of YAG nanoparticles has been reported [19-22]. Compared with conventional methods, microwave irradiation synthesis has advantages of short reaction time, production of small particles with narrow size distribution, and high purity $[23,24]$.

Recently, the microwave-assisted homogeneous precipitation method and microwave-assisted sol-gel method have been widely used for the synthesis of YAG and dopedYAG nanoparticles [25-27]. In these methods, some special addition agents are added to suppress agglomeration, such 
as ammonium sulfate $[12,23,25]$ and fluoride [14], but this will affect the purity of YAG. In addition, due to insufficient mixing and low reactivity of the raw materials, several intermediate phases such as $\mathrm{Y}_{4} \mathrm{Al}_{2} \mathrm{O}_{9}$ (YAM) and $\mathrm{YAlO}_{3}$ (YAP) easily exist in the products $[12,23]$. Some methods use a highpower microwave radiation, such as $800 \mathrm{~W}$ [23] and $900 \mathrm{~W}$ [25].

In this study, YAG nanoparticles have been synthesized by ultrasound-assisted and ultrasound-microwave-assisted alkoxide hydrolysis precipitation method. The effect of reaction parameters including $\mathrm{pH}$ value, ultrasonic radiation time, and calcination temperature on the composition of the products has been investigated. The morphology of YAG nanoparticles has been reported.

\section{Experimental}

2.1. Sample Synthesis. Al metal particles (99.99\% purity), Y metal particles (99.9\% purity), isopropanol, anhydrous aluminum chloride, and ammonium bicarbonate were employed as starting materials. First, the metal aluminum particles and proper amount of anhydrous aluminum chloride were added to isopropanol. The mixed solution was refluxed around $85^{\circ} \mathrm{C}$ until the aluminum isopropoxide was successfully prepared. Similarly, yttrium isopropoxide was also synthesized using the above-mentioned method. The prepared aluminum isopropoxide and yttrium isopropoxide were mixed (final mol ratio of $\mathrm{Al}$ ion : $\mathrm{Y}$ ion $=5: 3$ ). The mixed solution was added dropwise into the $1 \mathrm{~L}$ and $0.4 \mathrm{M}$ ammonium bicarbonate solution under ultrasound radiation at different $\mathrm{pH}$ value and ultrasound radiation times; the precipitate was aged for $16 \mathrm{~h}$ before filtration. After filtration and washing several times with distilled water and ethanol, the obtained sample was dried at $60^{\circ} \mathrm{C}$ overnight. Subsequently, the samples designated (a) were obtained after calcination at 900, 1000, and $1100^{\circ} \mathrm{C}$ for $2 \mathrm{~h}$. Furthermore, the YAG was synthesized by ultrasound-microwave-assisted alkoxide hydrolysis precipitation method. This synthesis method was the same as mentioned above, but the samples designated (b) underwent microwave radiation for a while instead of drying process after washing.

2.2. Analytical Methods. The crystalline phases of samples were confirmed by XRD using an Empyrean X-ray diffractometer with $\mathrm{Cu} \mathrm{K} \alpha$ radiation. DTA was characterized by SDT 2960 Simultaneous DSC-TGA (TA Instruments, USA) from room temperature up to $1000^{\circ} \mathrm{C}$ at a heating rate of $15^{\circ} \mathrm{C} / \mathrm{min}$ in $\mathrm{Ar}$ gas. FT-IR spectra were recorded using a Nicolet 380 spectrophotometer. TEM, SAED (selected area electron diffraction), HRTEM, and FFT (fast Fourier transform) of products were characterized by a JEM-2100F high-resolution transmission electron microscopy operated at an accelerating voltage of $200 \mathrm{kV}$.

\section{Results and Discussion}

3.1. Effect of $p H$ Value. Figure 1 shows the XRD patterns of YAG prepared by ultrasound-assisted synthesis (a) and ultrasound-microwave-assisted synthesis (b) at different $\mathrm{pH}$ values. In $\mathrm{pH}$ values of 8,9 , and 10 , all the diffracted peaks can be clearly indexed to pure phase of cubic YAG (JCPDS card number 73-1370), with no other peak corresponding to impurity observed. The sharp diffraction peaks of the sample indicated that well-crystallized YAG crystals can be easily obtained by ultrasound-assisted and ultrasound-microwaveassisted synthesis. Pure YAG phase is obtained in all samples, indicating weak influence of $\mathrm{pH}$ value on phase transformation.

3.2. Effect of Ultrasound Radiation Time. Figure 2(a) shows the XRD patterns of the prepared samples at different ultrasound radiation time by ultrasound-assisted synthesis. For radiation times of $3 \mathrm{~h}$ and $4 \mathrm{~h}$, there are two phases in the samples: YAG and YAM (JCPDS card number 14-0475), and the pure phase YAG can be obtained at $5 \mathrm{~h}$. Figure 2(b) shows the XRD patterns of the prepared samples at different ultrasound radiation time by ultrasound-microwave-assisted synthesis. As it is seen for radiation times of $3 \mathrm{~h}, 4 \mathrm{~h}$, and $5 \mathrm{~h}$, all of the diffracted peaks can be clearly indexed to pure phase of YAG, with no other peak corresponding to impurity observed.

3.3. Effect of Calcination Temperature. Figure 3(a) shows the XRD patterns of the prepared precursor and samples at different calcination temperatures by ultrasound-assisted synthesis. The precursor was of amorphous nature. The three phases YAG, YAP, and YAM were obtained when the calcination temperature of the precursor was $900^{\circ} \mathrm{C}$ and $1000^{\circ} \mathrm{C}$. The pure phase YAG can be obtained at $1100^{\circ} \mathrm{C}$. Figure $3(\mathrm{~b})$ shows the XRD patterns of the prepared precursor and samples at different calcination temperatures by ultrasound-microwaveassisted synthesis. As it is seen, the precursor was also of amorphous nature. The samples heated up to $900^{\circ} \mathrm{C}$ were amorphous with weak crystalline peaks of YAG; sharp peaks appeared for the samples calcined at $1000-1100^{\circ} \mathrm{C}$, which were in good agreement with the standard JCPDS file of YAG. The results show that the single ultrasound-assisted method to synthesize YAG phase often contains intermediate phases of YAM and YAP, and pure YAG phase can form only at special conditions. The pure phase YAG powders were obtained at each experimental condition when using ultrasoundmicrowave-assisted synthesis. The absence of the intermediate phases (YAM, YAP) during the heating process is because the component of the precursor is more uniform compared with the conventional heating techniques. Under microwave irradiation, a large number of crystal nuclei of precursor burst quickly at the same time, avoiding $\mathrm{Al}^{3+}$ and $\mathrm{Y}^{3+}$ to precipitate sequentially. Besides, the uniform distribution of $\mathrm{Al}^{3+}$ and $\mathrm{Y}^{3+}$ on the ion level also shortens the diffusion distance and lowers the synthesizing temperature of pure-phase YAG.

3.4. DTA Analysis. Figure 4 shows the DTA curves of the precursors of YAG prepared by ultrasound-assisted synthesis (a) and ultrasound-microwave-assisted synthesis (b). The exothermic peaks were observed at $920^{\circ} \mathrm{C}$ (a) and $930^{\circ} \mathrm{C}$ (b). These peaks were attributed to the crystallization of the 


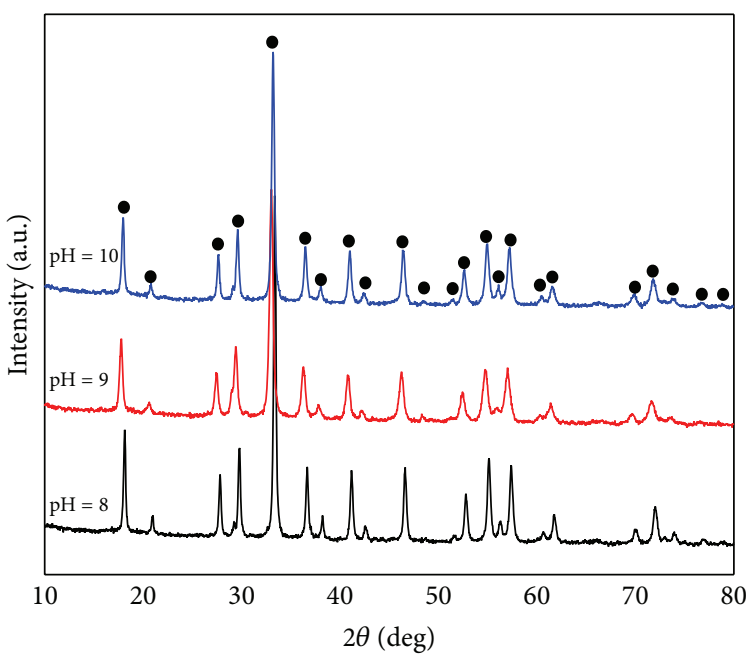

- YAG

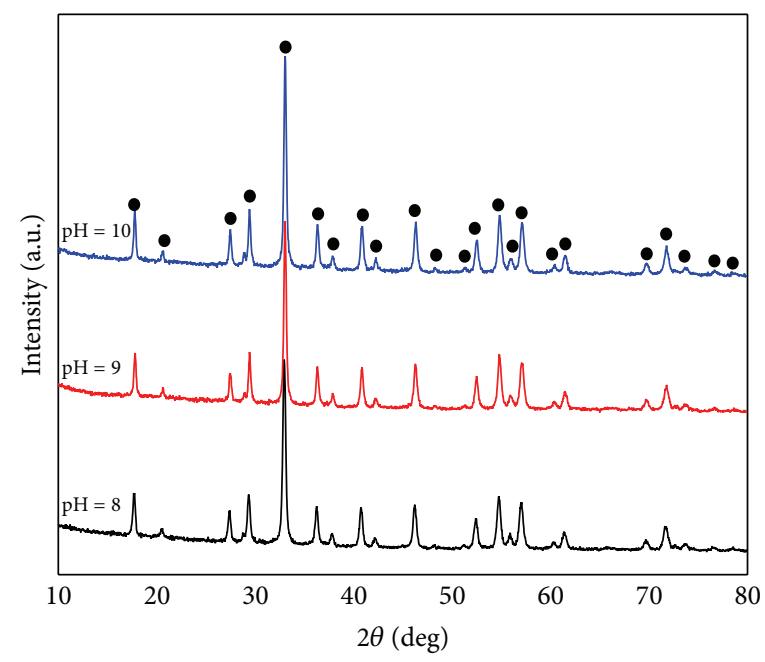

- YAG

(a)

(b)

FIGURE 1: XRD patterns of YAG prepared by ultrasound-assisted synthesis (a) and ultrasound-microwave-assisted synthesis (b) at pH $~ 8-10$.

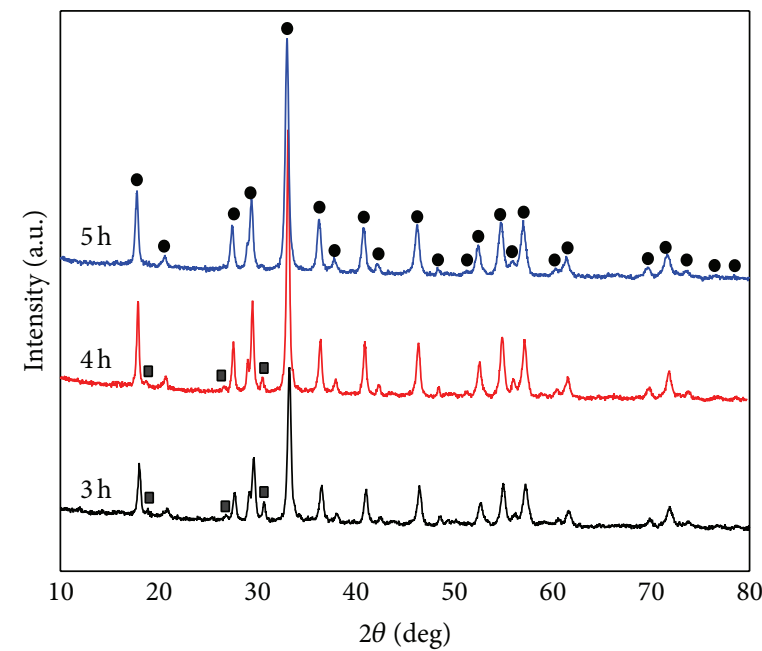

- YAG

- YAM

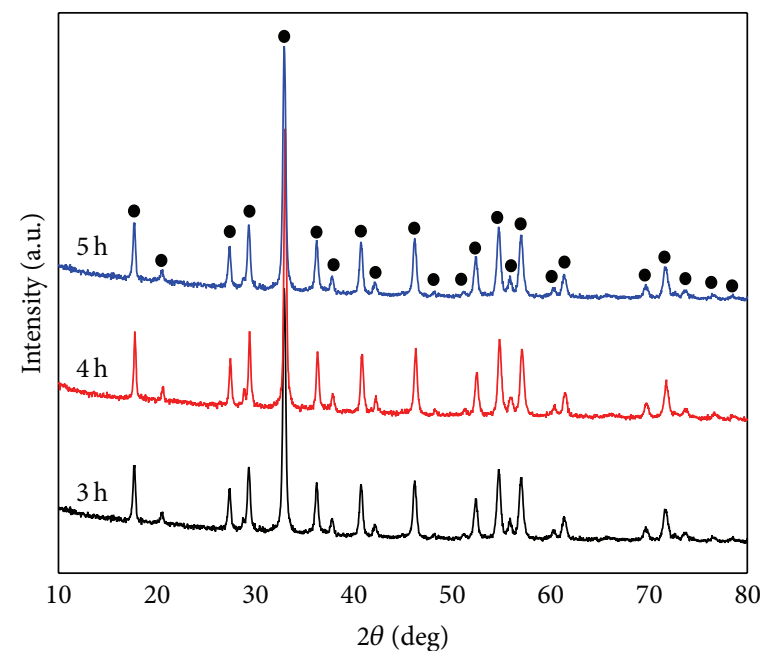

- YAG

(a)

(b)

FIGURE 2: XRD patterns of YAG prepared by ultrasound-assisted synthesis (a) and an ultrasound-microwave-assisted synthesis (b) at ultrasound radiation times $\sim 3 \mathrm{~h}-5 \mathrm{~h}$.

precursors. The crystallization points are similar to those reported in the literature [28]. This result is well in accordance with the experimental result of XRD. There are two noteworthy peaks, arrowed in Figure 4, which are weakened when using ultrasound-microwave-assisted synthesis. This shows that the precursor undergoes certain reaction when using ultrasound-microwave-assisted synthesis.

3.5. FT-IR Analysis. Figure 5 shows the FT-IR spectra of precursor of YAG prepared by ultrasound-assisted synthesis (a) and ultrasound-microwave-assisted synthesis (b), in which the wide band at $3000 \sim 3750 \mathrm{~cm}^{-1}$ should be due to the stretching of $\mathrm{O}-\mathrm{H}$ in water, and the $\mathrm{NH}_{4}^{+}$can be detected at $2884 \mathrm{~cm}^{-1}$. The band at $1300-1610 \mathrm{~cm}^{-1}$ indicates the presence of $\mathrm{CO}_{3}{ }^{2-}$, and the band at about $1072 \mathrm{~cm}^{-1}$ should be due to the stretching of $\mathrm{C}-\mathrm{O}$. In addition the band at $478-$ $850 \mathrm{~cm}^{-1}$ should be assigned to the bending of $\mathrm{Al}-\mathrm{OH}$ and $\mathrm{Y}-\mathrm{OH}[29,30]$. FT-IR spectra analysis shows that the two precursors are basic carbonate. The peak intensity of Figure 5(b) is found to be enhancing due to added microwave irradiation, which was beneficial to crystal nuclei simultaneous formation of yttrium ion, aluminum ion, and other anions. 


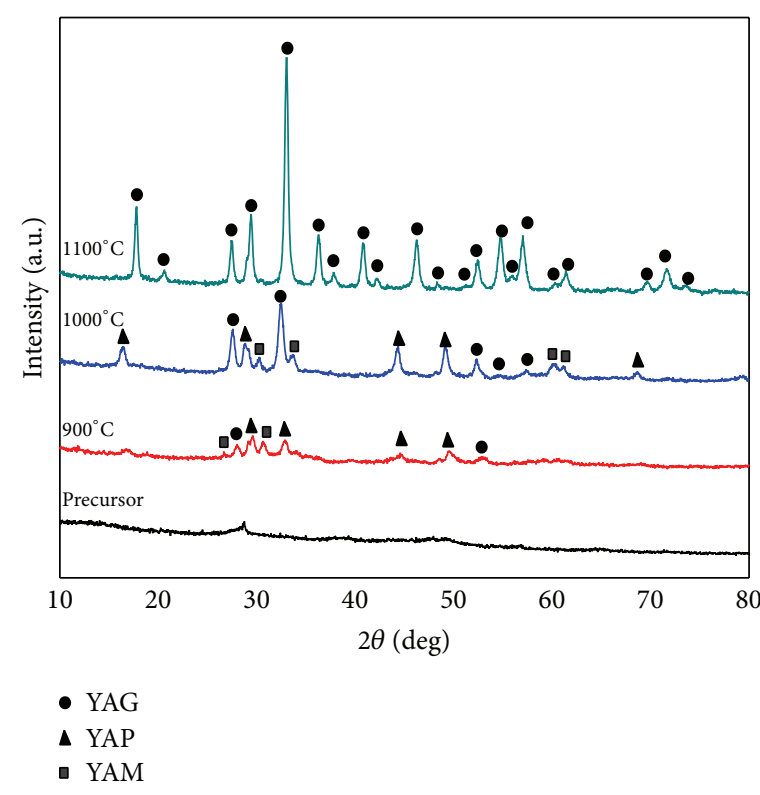

(a)

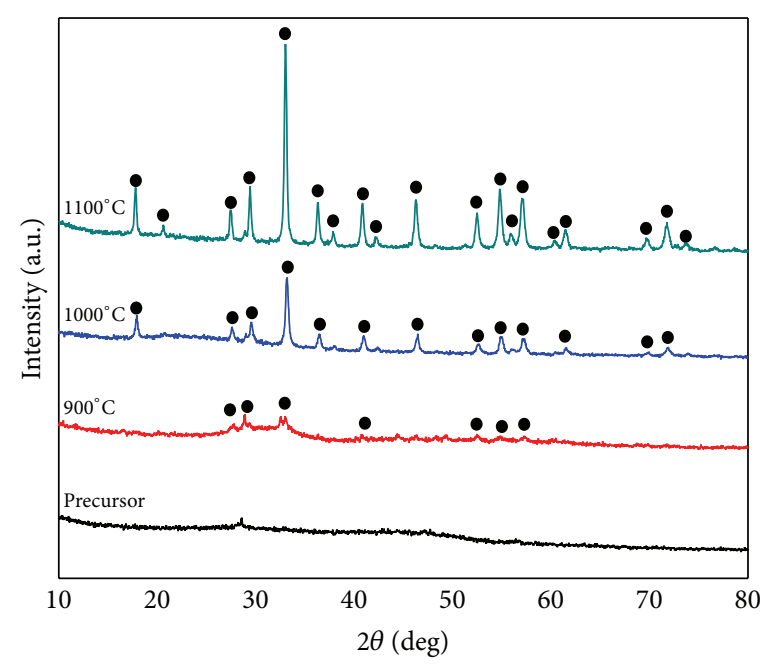

- YAG

FIGURE 3: XRD patterns of YAG prepared by ultrasound-assisted synthesis (a) and ultrasound-microwave-assisted synthesis (b) at calcination temperature $\sim 900-1100^{\circ} \mathrm{C}$ and their precursors.

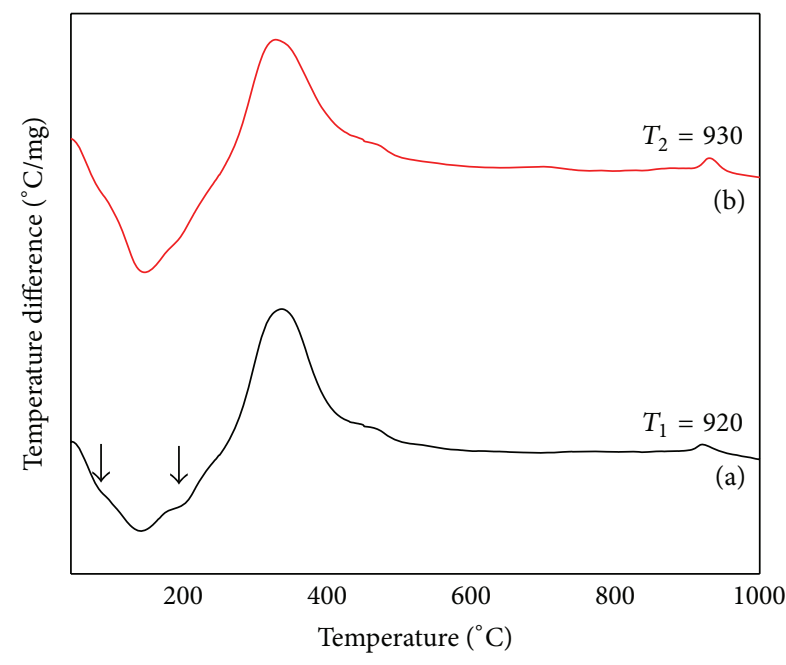

FIGURE 4: DTA curves of the precursors of YAG prepared by ultrasound-assisted synthesis (a) and ultrasound-microwaveassisted synthesis (b).

3.6. Morphology Analysis. The morphology of the as-prepared sample is characterized with TEM, SAED, FFT, and HRTEM. Figures 6(a) and 6(c) show that the precursors, which were prepared by ultrasound-assisted synthesis (I) and ultrasound-microwave-assisted synthesis (II), have colloidal structure and the average diameters of about $15 \mathrm{~nm}$ and $30 \mathrm{~nm}$, respectively. Figure 6(b) shows that the precursor (I) calcined at $1100^{\circ} \mathrm{C}$ has hierarchical nanostructure and average diameter of about $50 \mathrm{~nm}$. Figures 6(d) and 6(e) show that the precursor (II) calcined at $900^{\circ} \mathrm{C}$ and $1000^{\circ} \mathrm{C}$ has equiaxed grain nanostructure with average diameter of about

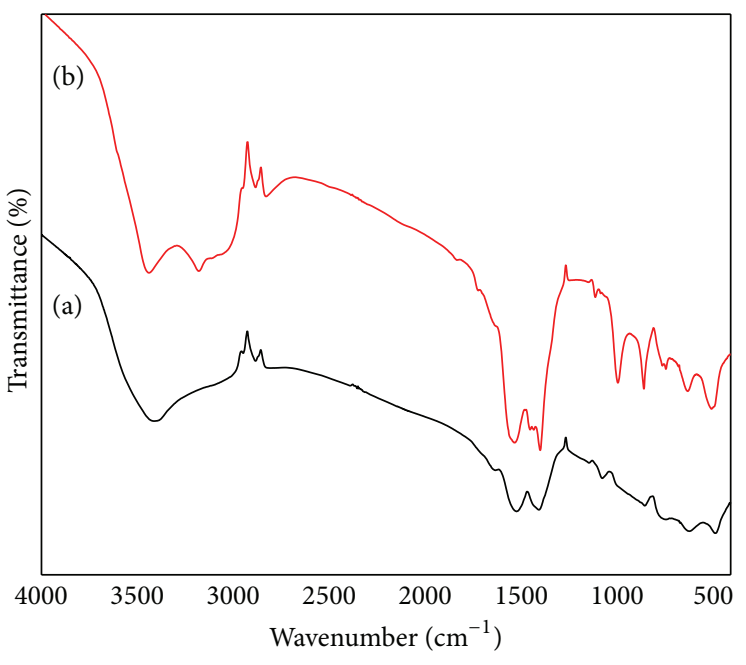

FIGURE 5: FT-IR spectra of precursor of YAG prepared by ultrasound-assisted synthesis (a) and ultrasound-microwave-assisted synthesis (b).

$18 \mathrm{~nm}$ and $23 \mathrm{~nm}$, respectively. Figure 6(f) shows that the hierarchical nanostructures of YAG with a size of $42 \mathrm{~nm}$ were produced due to agglomeration at high calcination temperature $\left(1100^{\circ} \mathrm{C}\right)$. Compared with single ultrasound-assisted method, ultrasound-microwave-assisted alkoxide hydrolysis precipitation method has advantages for production of particles with narrow size distribution and uniform form.

Figure 7(a) shows the SAED pattern of YAG prepared by ultrasound-assisted synthesis. The dot corresponds to the diffraction from the (211) plane of YAG. Figure 7(b) shows the HRTEM image and FFT pattern (see illustration) of YAG 


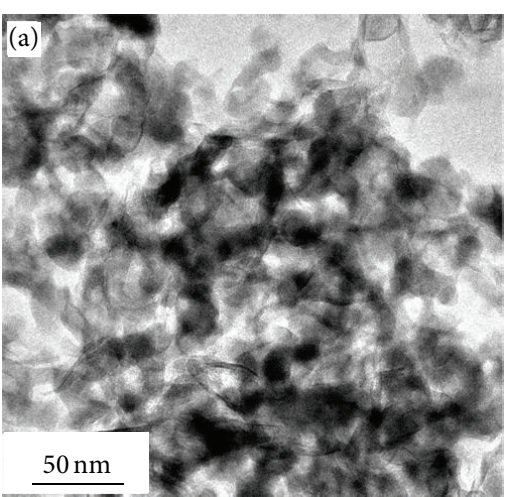

(a)

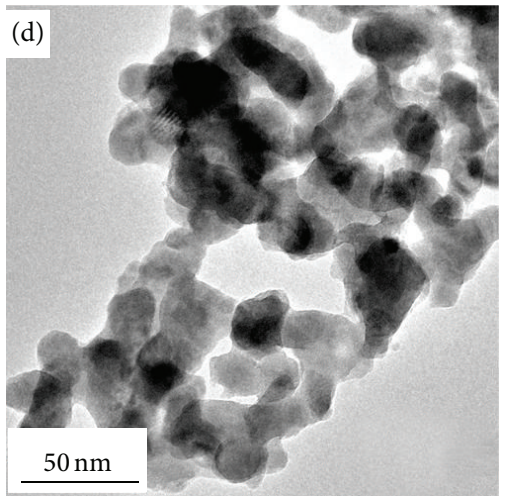

(d)

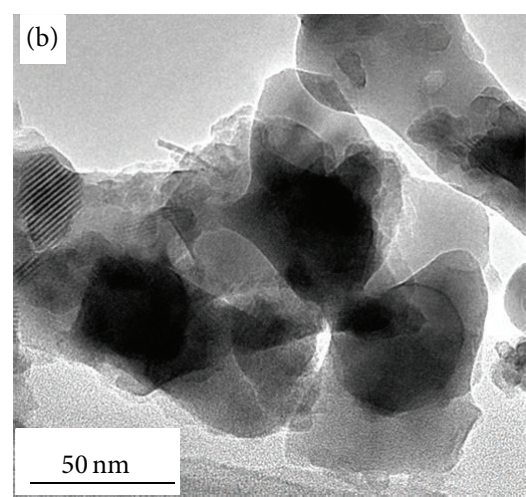

(b)

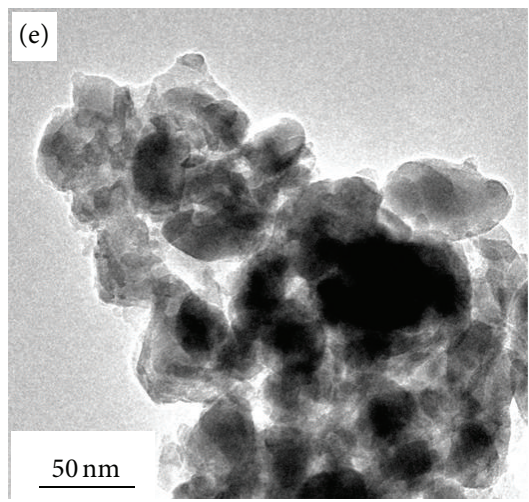

(e)

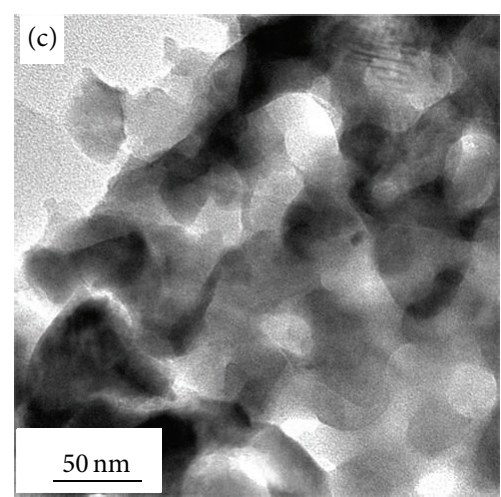

(c)

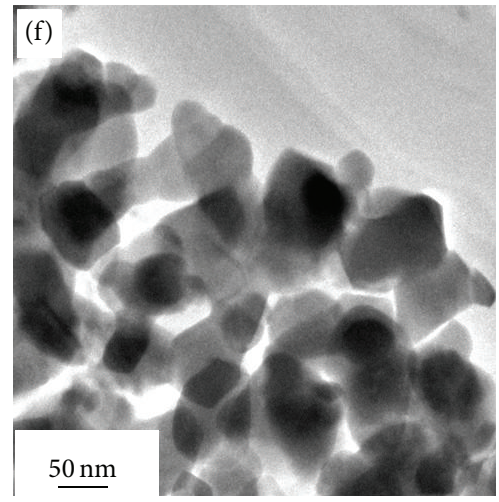

(f)

FIGURE 6: TEM images of the samples prepared by ultrasound-assisted synthesis ((a) precursor I; (b) precursor I calcined at $1100^{\circ} \mathrm{C}$ ) and ultrasound-microwave-assisted synthesis ((c) precursor II, (d) precursor II calcined at $900^{\circ} \mathrm{C}$, (e) precursor II calcined at $1000^{\circ} \mathrm{C}$, and (f) precursor II calcined at $1100^{\circ} \mathrm{C}$ ).

prepared by ultrasound-assisted synthesis. In Figures 7(a) and 7(b), the structure of YAG is single crystalline and crystal grains grow along the same direction. Figure 7(c) shows the SAED pattern of YAG prepared by ultrasound-microwave-assisted synthesis. The rings correspond to the diffraction from the (220), (400), and (420) planes of YAG. Figure 7(d) shows the HRTEM image and FFT pattern (see illustration) of YAG prepared by ultrasound-microwave-assisted synthesis. In Figures 7(c) and 7(d), the structure of YAG is polycrystalline and crystal grains grow in random orientations.

Figure 8 shows the schematic diagram of the growth mechanism of YAG prepared by ultrasound-assisted synthesis (I) and ultrasound-microwave-assisted synthesis (II). In this experiment, the aluminum isopropoxide and yttrium isopropoxide were added dropwise at the same time into the ammonium bicarbonate solution under ultrasound radiation. The alkoxide hydrolysis and precipitation process were carried out simultaneously. The particle size and distribution of prepared precipitate depend on the growth rate $v_{1}$ of crystal nucleus of the precipitate and growth rate $v_{2}$ of the crystal. According to the Wennarn-Tamman Theory: $v_{1}=k(Q-L) / L$, $v_{2}=D S(Q-L) / \delta$, wherein $k$ is constant, $Q$ is the concentration of the resulting precipitate at adding a precipitating agent instantly, $L$ is solubility of substances, $(Q-L)$ is supersaturation degree of precipitate, $D$ is the diffusion coefficient in the solution, $S$ is surface area, and $\delta$ is diffusion path.

Apparently, the larger the growth rate $v_{1}$ of crystal nucleus, the more the number of crystal nuclei formed in unit time and the smaller the grain. To obtain YAG powder with uniform distribution and small grain size, the experiment used ultrasound-assisted alkoxide hydrolysis precipitation method. This is because the ultrasonic cavitation has obvious influence on the crystal nucleation and growth. Ultrasonic fields can promote formation of crystal nuclei and a lot of cavitation bubbles can also cause micro eddy current on the surface of particles, playing a role in stirring and accelerating the diffusion of the reaction system. Consequently, the thermodynamically unstable crystal nuclei can grow up to be stable particles by diffusing and capturing groups in reaction solution.

These stable crystal nuclei can rapidly reduce supersaturation of solution and inhibit secondary nucleation and further growth of crystal nuclei. When using ultrasoundassisted alkoxide hydrolysis precipitation method, it can prevent particle size distribution from becoming broader along with increasing local elative supersaturation degree of crystal nucleus. As a matter of fact, when using single alkoxide hydrolysis method, this kind of circumstance often appears. 


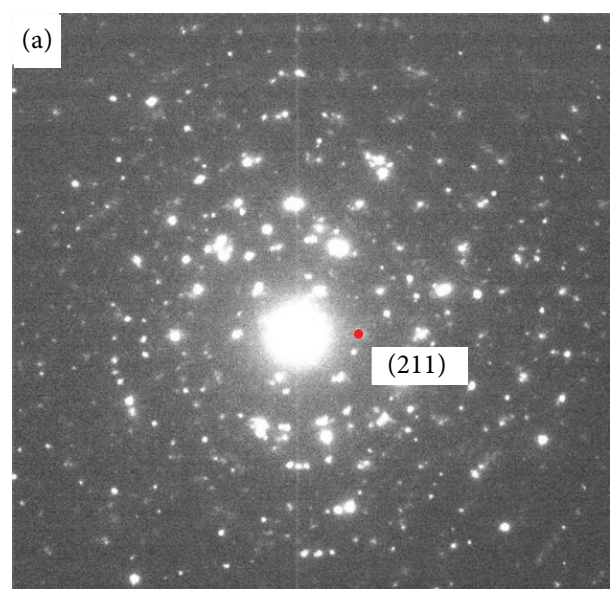

(a)

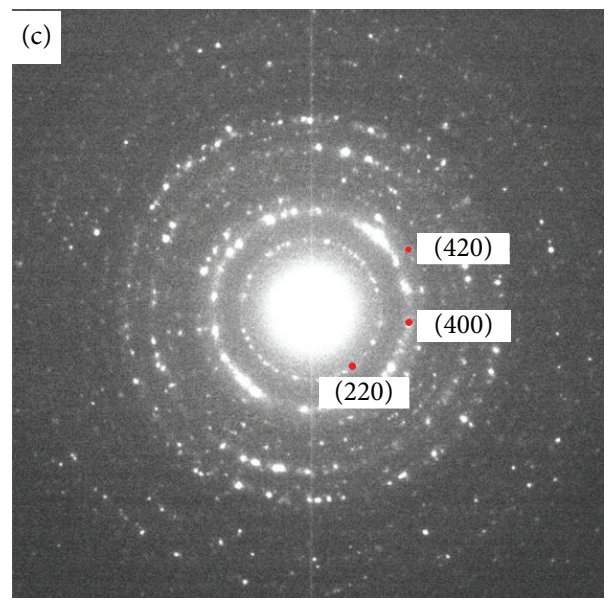

(c)

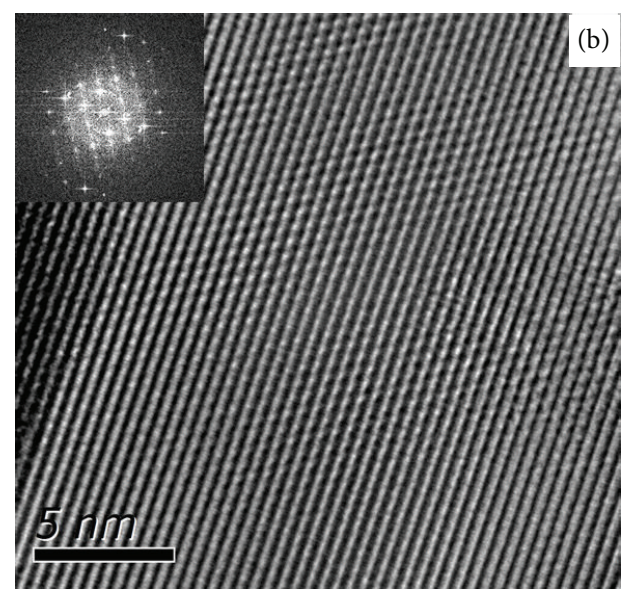

(b)

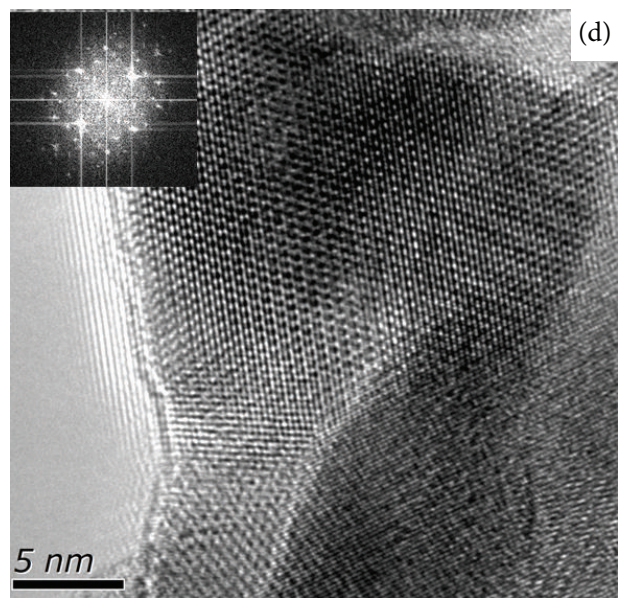

(d)

FIGURE 7: (a) SAED pattern, (b) HRTEM image of YAG prepared by ultrasound-assisted synthesis, (c) SAED pattern, and (d) HRTEM image of YAG prepared by ultrasound-microwave-assisted synthesis. Inset shows the FFT pattern of corresponding YAG.

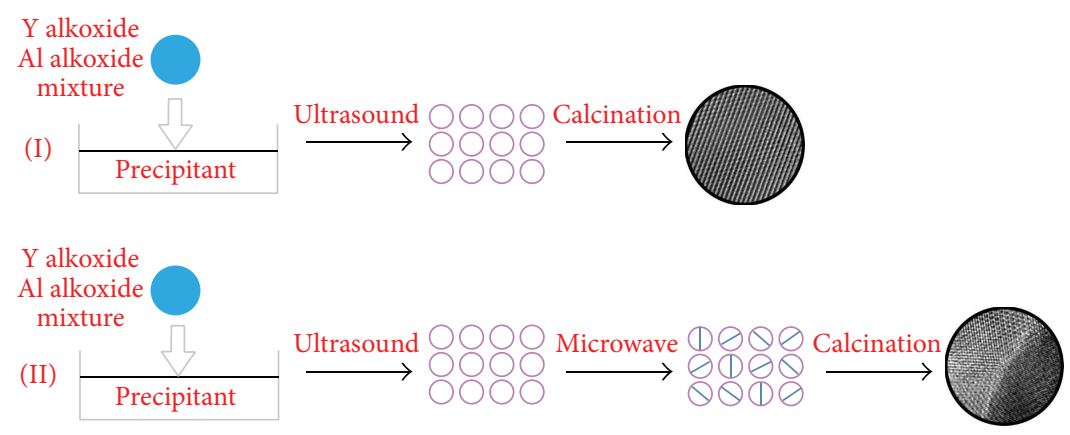

FIGURE 8: Schematic diagram of the growth mechanism of YAG prepared by ultrasound-assisted synthesis (I) and ultrasound-microwaveassisted synthesis (II).

Under ultrasonic irradiation, the growth rate of all orientations was simultaneously increased in nuclei. The single crystal nanoparticles with good dispersion and narrow size distribution were obtained through calcining its precursor (see Figure 8(I)).
When further using ultrasound-microwave-assisted alkoxide hydrolysis precipitation method (see Figure 8(II)), a large number of nuclei of precursor were produced like explosion, and $\mathrm{Y}^{3+}, \mathrm{Al}^{3+}$ cations and related anions nucleated at the same time, avoiding precipitate of ions step by step in 
conventional heating. Because the growth rate $v_{1}$ of crystal nucleus is greater than the growth rate $v_{2}$ of crystal, the particles size of precursor was even finer and uniform. Vibration of microwave can drive molecular movement and have effect on energy distribution at different crystal planes and growth directions of different nuclei. The polycrystalline crystal nanoparticles with good dispersibility and uniform size were obtained through calcining its precursor.

Recalling our data, Figure 4 shows that the precursor undergoes certain reaction when using ultrasound-microwave-assisted method. So, pure phase YAG can be obtained at each reaction condition and without intermediate phases YAM and YAP. Consequently, when using ultrasound-microwave-assisted alkoxide hydrolysis precipitation method, the particles size of YAG is finer and uniform without any additives.

\section{Conclusion}

YAG nanoparticles were synthesized by ultrasound-assisted and ultrasound-microwave-assisted alkoxide hydrolysis precipitation method. Conditions for the single ultrasoundassisted method to synthesize YAG pure phase are ultrasonic radiation for $5 \mathrm{~h}$, calcination temperature at $1100^{\circ} \mathrm{C}$, and $\mathrm{pH}$ values between 8 and 10. Using ultrasound-microwaveassisted synthesis under various conditions can yield pure phase YAG, which is due to the rapid formation of a large number of YAG induced nuclei in synthetic precursor after further microwave treatment. In this case, YAG nanoparticles with finer grain size and uniform dispersion were prepared. In particular, the YAG nanoparticles with $18 \mathrm{~nm}$ grain size can be obtained at a calcination temperature of $900^{\circ} \mathrm{C}$.

Further studies are needed to understand the detailed mechanism of microwave on amorphous precursor. These studies are in progress and will be reported at a later stage.

\section{Conflict of Interests}

The authors declare that there is no conflict of interests regarding the publication of this paper.

\section{Acknowledgments}

This work was supported by the National Natural Science Foundation of China (51308086) and the Scientific Research Fund of Liaoning Provincial Education Department of China (L2012161).

\section{References}

[1] D. K. Christoulis, S. Guetta, E. Irissou et al., "Cold-spraying coupled to nano-pulsed Nd-YaG laser surface pre-treatment," Journal of Thermal Spray Technology, vol. 19, no. 5, pp. 10621073, 2010.

[2] P. K. Sharma, R. K. Dutta, and A. C. Pandey, "Performance of YAG:Eu ${ }^{3+}$, YAG: $\mathrm{Tb}^{3+}$ and BAM:Eu ${ }^{2+}$ plasma display nanophosphors," Journal of Nanoparticle Research, vol. 14, no. 3, article 731, 2012.

[3] X. Li, H. Liu, J. Y. Wang et al., "Rapid synthesis of YAG nanosized powders by a novel method," Materials Letters, vol. 58, no. 19, pp. 2377-2380, 2004.
[4] O. T. Even-Zur and R. Chaim, "Effect of green density and electric field direction on densification of YAG nano-powders by spark plasma sintering," Journal of Materials Science, vol. 44, no. 8, pp. 2063-2068, 2009.

[5] H. Sun, X. Zhang, and Z. Bai, "Synthesis and characterization of nano-sized YAG:Ce, Sm spherical phosphors," Journal of Rare Earths, vol. 31, no. 3, pp. 231-234, 2013.

[6] Y. H. Song, T. Y. Choi, T. Masaki, K. Senthil, and D. H. Yoon, "Photoluminescence properties and synthesis of nanosized YAG: $\mathrm{Ce}^{3+}$ phosphor via novel synthesis method," Current Applied Physics, vol. 12, no. 2, pp. 479-482, 2012.

[7] A. Tarafder, A. R. Molla, and B. Karmakar, "Effects of nanoYAG $\left(\mathrm{Y}_{3} \mathrm{Al}_{5} \mathrm{O}_{12}\right)$ crystallization on the structure and photoluminescence properties of $\mathrm{Nd}^{3+}$-doped $\mathrm{K}_{2} \mathrm{O}-\mathrm{SiO}_{2}-\mathrm{Y}_{2} \mathrm{O}_{3}-\mathrm{Al}_{2} \mathrm{O}_{3}$ glasses," Solid State Sciences, vol. 12, no. 10, pp. 1756-1763, 2010.

[8] J. Y. Chong, Y. Zhang, B. K. Wagner, and Z. Kang, "Co-precipitation synthesis of YAG:Dy nanophosphor and its thermometric properties," Journal of Alloys and Compounds, vol. 581, pp. 484-487, 2013.

[9] W. Gao, Y. Hu, W. Zhuang, S. Zhang, Y. Liu, and H. He, "A novel method for the synthesis of YAG:Ce phosphor," Journal of Rare Earths, vol. 27, no. 6, pp. 886-890, 2009.

[10] E. Caponetti, M. L. Saladino, F. Serra, and S. Enzo, "Co-precipitation synthesis of Nd:YAG nano-powders: the effect of $\mathrm{Nd}$ dopant addition with thermal treatment," Journal of Materials Science, vol. 42, no. 12, pp. 4418-4427, 2007.

[11] S. Yang, W. Que, J. Chen, and W. G. Liu, "Nd:YAG nano-crystalline powders derived by combining co-precipitation method with citric acid treatment," Ceramics International, vol. 38, no. 4, pp. 3185-3189, 2012.

[12] Y. H. Lv, W. Zhang, H. Liu et al., "Synthesis of nano-sized and highly sinterable Nd:YAG powders by the urea homogeneous precipitation method," Powder Technology, vol. 217, pp. 140-147, 2012.

[13] K. Guo, M.-L. Huang, H.-H. Chen, X.-X. Yang, and J.-T. Zhao, "Comparative study on photoluminescence of amorphous and nano-crystalline YAG:Tb phosphors prepared by a combustion method," Journal of Non-Crystalline Solids, vol. 358, no. 1, pp. 88-92, 2012.

[14] H. Jiao, Q. Ma, L. He, Z. Liu, and Q. Wu, "Low temperature synthesis of YAG:Ce phosphors by LiF assisted sol-gel combustion method," Powder Technology, vol. 198, no. 2, pp. 229-232, 2010.

[15] Y. You, L. Qi, X. Li, and W. Pan, "Preparation of YAG nanopowders via an ultrasonic spray co-precipitation method," Ceramics International, vol. 39, no. 4, pp. 3987-3992, 2013.

[16] M. A. Alavi and A. Morsali, "Syntheses and characterization of $\mathrm{Mg}(\mathrm{OH})_{2}$ and $\mathrm{MgO}$ nanostructures by ultrasonic method," Ultrasonics Sonochemistry, vol. 17, no. 2, pp. 441-446, 2010.

[17] J. Wang, S. Y. Zhou, J. Wang et al., "Improvement of sonocatalytic activity of $\mathrm{TiO}_{2}$ by using $\mathrm{Yb}, \mathrm{N}$ and F-doped $\mathrm{Er}^{3+}: \mathrm{Y}_{3} \mathrm{Al}_{5} \mathrm{O}_{12}$ for degradation of organic dyes," Ultrasonics Sonochemistry, vol. 21, no. 1, pp. 84-92, 2014.

[18] A. Pendashteh, M. S. Rahmanifar, and M. F. Mousavi, "Morphologically controlled preparation of $\mathrm{CuO}$ nanostructures under ultrasound irradiation and their evaluation as pseudocapacitor materials," Ultrasonics Sonochemistry, vol. 21, no. 2, pp. 643-652, 2014.

[19] L. Esposito, A. Piancastelli, Y. Bykov, S. Egorov, and A. Eremeev, "Microwave sintering of Yb:YAG transparent laser ceramics," Optical Materials, vol. 35, no. 4, pp. 761-765, 2013. 
[20] A. Bhaskar, H.-Y. Chang, T.-H. Chang, and S.-Y. Cheng, "Microwave annealing of YAG: Ce nanophosphors," Materials Letters, vol. 78, pp. 124-126, 2012.

[21] C. Ren, Y. He, and D. Wang, "High-temperature cyclic oxidation behavior of $\mathrm{Al}_{2} \mathrm{O}_{3}$-YAG composite coating prepared by EPD and microwave sintering," Applied Surface Science, vol. 258, no. 15, pp. 5739-5745, 2012.

[22] C. Padmavathi, A. Upadhyaya, and D. Agrawal, "Corrosion behavior of microwave-sintered austenitic stainless steel composites," Scripta Materialia, vol. 57, no. 7, pp. 651-654, 2007.

[23] X. Zhang, D. Liu, H. Liu, J. Wang, H. Qin, and Y. Sang, "Microstructural characteristics of Nd:YAG powders leading to transparent ceramics," Journal of Rare Earths, vol. 29, no. 6, pp. 585591, 2011.

[24] K. Y. Jung and Y. C. Kang, "Luminescence comparison of YAG:Ce phosphors prepared by microwave heating and precipitation methods," Physica B: Condensed Matter, vol. 405, no. 6, pp. 1615-1618, 2010.

[25] Y. Wang, P. Yuan, H. Xu, and J. Wang, "Synthesis of Ce:YAG phosphor via homogeneous precipitation under microwave irradiation," Journal of Rare Earths, vol. 24, no. 1, pp. 183-186, 2006.

[26] M. L. Saladino, G. Nasillo, D. C. Martino, and E. Caponetti, "Synthesis of Nd:YAG nanopowder using the citrate method with microwave irradiation," Journal of Alloys and Compounds, vol. 491, no. 1-2, pp. 737-741, 2010.

[27] P. F. S. Pereira, J. M. A. Caiut, S. J. L. Ribeiro et al., "Microwave synthesis of YAG:Eu by sol-gel methodology," Journal of Luminescence, vol. 126, no. 2, pp. 378-382, 2007.

[28] L. Zhang, Z. Lu, J. Zhu et al., "Citrate sol-gel combustion preparation and photoluminescence properties of YAG:Ce phosphors," Journal of Rare Earths, vol. 30, no. 4, pp. 289-296, 2012.

[29] R. Malekfar and S. Arabgari, "Temperature effects on the structure and morphology of Nd:YAG nanocrystallites," Current Applied Physics, vol. 11, no. 4, pp. 1077-1082, 2011.

[30] S. N. Bagayev, A. A. Kaminskii, Y. L. Kopylov, and V. B. Kravchenko, "Problems of YAG nanopowders compaction for laser ceramics," Optical Materials, vol. 33, no. 5, pp. 702-705, 2011. 

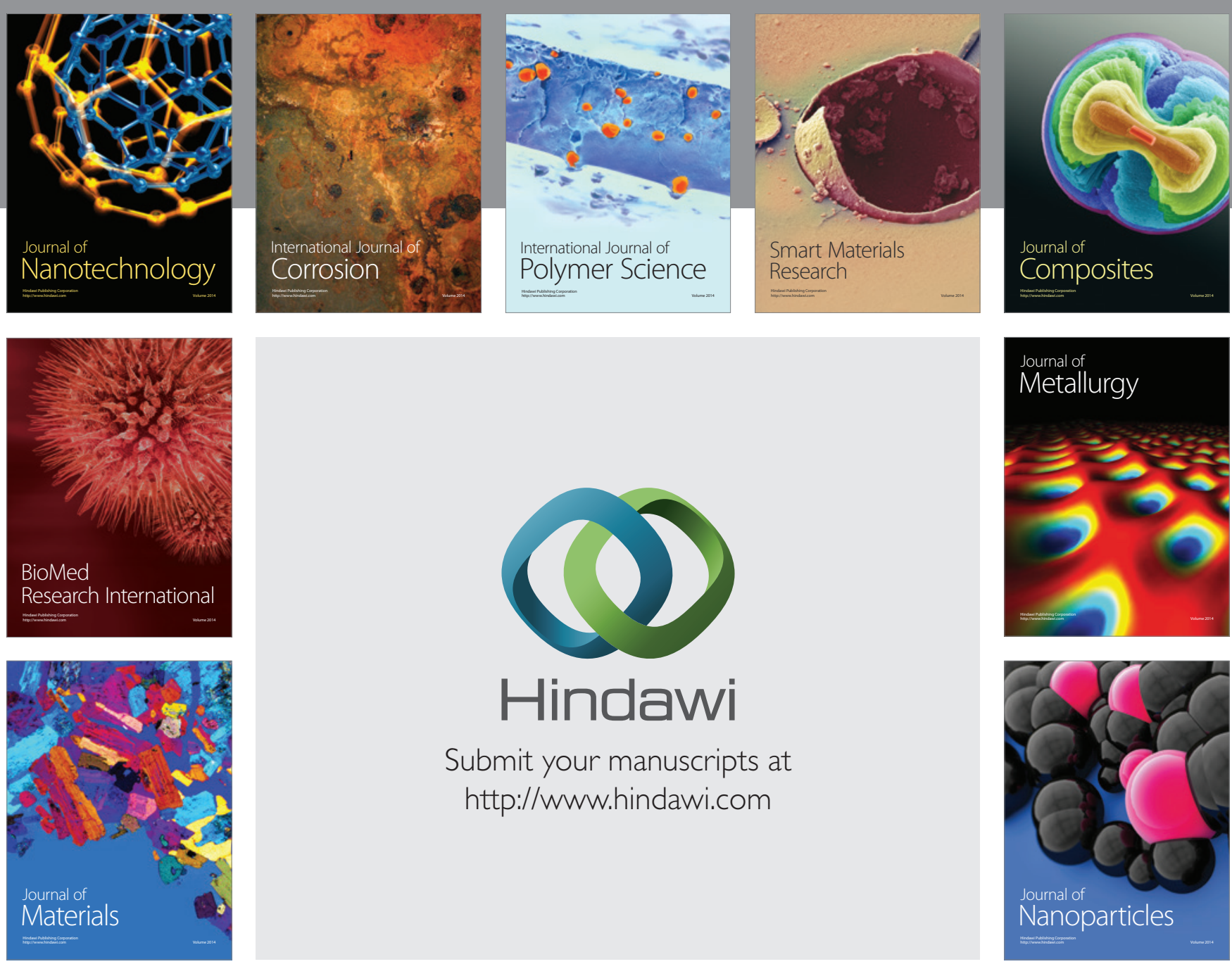

Submit your manuscripts at http://www.hindawi.com
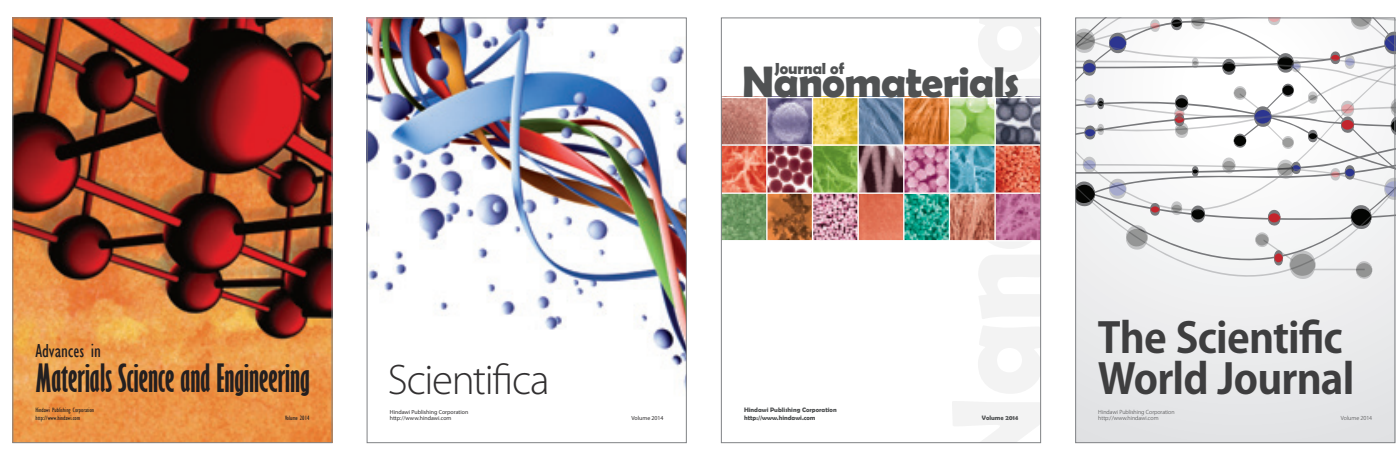

\section{The Scientific World Journal}
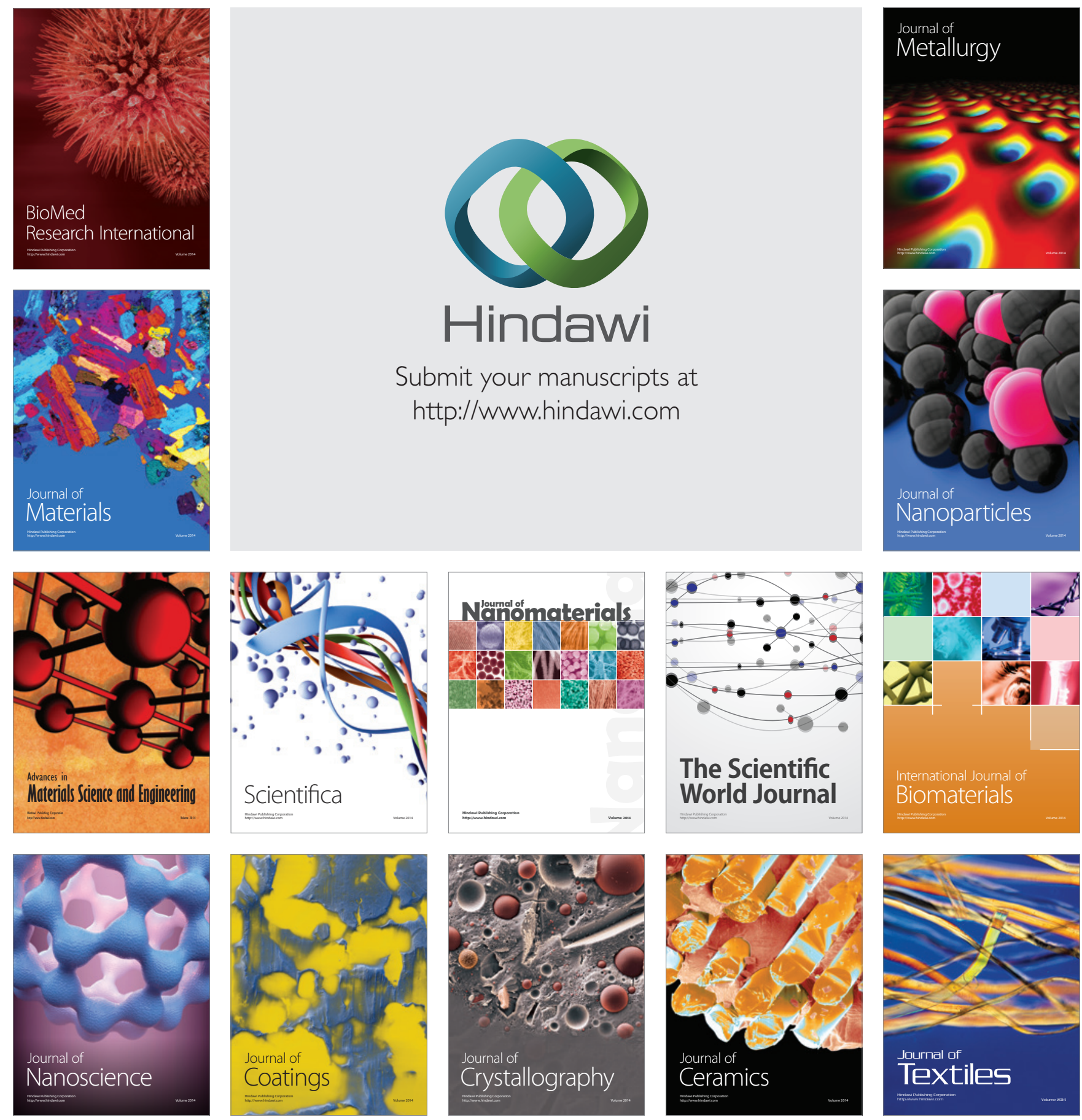